University of Nebraska - Lincoln

DigitalCommons@University of Nebraska - Lincoln

US Army Research

U.S. Department of Defense

2010

Inflammatory effects of inhaled sulfur mustard in rat lung

\author{
Rama Malaviya \\ Rutgers University \\ Vasanthi R. Sunil \\ Rutgers University \\ Jessica Cervelli \\ Rutgers University \\ Dana R. Anderson \\ US Army Medical Research Institute of Chemical Defense \\ Wesley W. Holmes \\ US Army Medical Research Institute of Chemical Defense \\ See next page for additional authors
}

Follow this and additional works at: https://digitalcommons.unl.edu/usarmyresearch

Part of the Operations Research, Systems Engineering and Industrial Engineering Commons

\footnotetext{
Malaviya, Rama; Sunil, Vasanthi R.; Cervelli, Jessica; Anderson, Dana R.; Holmes, Wesley W.; Conti, Michele L.; Gordon, Ronald E.; Laskin, Jeffrey D.; and Laskin, Debra L., "Inflammatory effects of inhaled sulfur mustard in rat lung" (2010). US Army Research. 137.

https://digitalcommons.unl.edu/usarmyresearch/137

This Article is brought to you for free and open access by the U.S. Department of Defense at DigitalCommons@University of Nebraska - Lincoln. It has been accepted for inclusion in US Army Research by an authorized administrator of DigitalCommons@University of Nebraska - Lincoln.
} 


\section{Authors}

Rama Malaviya, Vasanthi R. Sunil, Jessica Cervelli, Dana R. Anderson, Wesley W. Holmes, Michele L. Conti, Ronald E. Gordon, Jeffrey D. Laskin, and Debra L. Laskin 


\title{
Inflammatory effects of inhaled sulfur mustard in rat lung
}

\author{
Rama Malaviya ${ }^{\text {a }}$, Vasanthi R. Sunil ${ }^{a}$, Jessica Cervelli ${ }^{a}$, Dana R. Anderson ${ }^{\text {b }}$, Wesley W. Holmes ${ }^{\text {b }}$, \\ Michele L. Conti ${ }^{\mathrm{b}}$, Ronald E. Gordon ${ }^{\mathrm{c}}$, Jeffrey D. Laskin ${ }^{\mathrm{d}}$, Debra L. Laskin ${ }^{\mathrm{a}, *}$ \\ a Department of Pharmacology and Toxicology, Rutgers University, Piscataway, NJ 08854, USA \\ b Analytical Toxicology Division, US Army Medical Research Institute of Chemical Defense, Aberdeen, MD 21010, USA \\ c Department of Pathology, Mount Sinai School of Medicine, New York, NY 10029, USA \\ d Department of Environmental and Occupational Medicine, UMDNJ-Robert Wood Johnson Medical School, Piscataway, NJ 08854, USA
}

\section{A R T I C L E I N F O}

\section{Article history:}

Received 28 April 2010

Revised 16 July 2010

Accepted 19 July 2010

Available online 24 July 2010

\section{Keywords:}

Vesicant

Sulfur mustard

Inflammation

Lung

Apoptosis

Autophagy

\begin{abstract}
A B S T R A C T
Inhalation of sulfur mustard (SM), a bifunctional alkylating agent that causes severe lung damage, is a significant threat to both military and civilian populations. The mechanisms mediating its cytotoxic effects are unknown and were investigated in the present studies. Male rats $\mathrm{Crl}: \mathrm{CD}(\mathrm{SD})$ were anesthetized, and then intratracheally intubated and exposed to $0.7-1.4 \mathrm{mg} / \mathrm{kg}$ SM by vapor inhalation. Animals were euthanized 6 , $24,48 \mathrm{~h}$ or 7 days post-exposure and bronchoalveolar lavage fluid (BAL) and lung tissue collected. Exposure of rats to SM resulted in rapid pulmonary toxicity, including focal ulceration and detachment of the trachea and bronchial epithelia from underlying mucosa, thickening of alveolar septal walls and increased numbers of inflammatory cells in the tissue. There was also evidence of autophagy and apoptosis in the tissue. This was correlated with increased BAL protein content, a marker of injury to the alveolar epithelial lining. SM exposure also resulted in increased expression of markers of inflammation including cyclooxygenase- 2 (COX-2), tumor necrosis factor- $\alpha$ (TNF $\alpha$ ), inducible nitric oxide synthase (iNOS), and matrix metalloproteinase-9 (MMP-9), each of which has been implicated in pulmonary toxicity. Whereas COX-2, TNF $\alpha$ and iNOS were mainly localized in alveolar regions, MMP-9 was prominent in bronchial epithelium. In contrast, expression of the anti-oxidant hemeoxygenase, and the anti-inflammatory collectin, surfactant protein-D, decreased in the lung after SM exposure. These data demonstrate that SM-induced oxidative stress and injury are associated with the generation of cytotoxic inflammatory proteins which may contribute to the pathogenic response to this vesicant.
\end{abstract}

(c) 2010 Published by Elsevier Inc.

\section{Introduction}

Sulfur mustard (SM, 2-bis-chloroethyl-sulfide) is a highly toxic vesicant that has been used as a chemical warfare agent. The severity of damage largely depends on the dose and duration of exposure. A major target of SM is the lung and most mortality following SM poisoning is due to pulmonary damage and associated infections (Kehe and Szinicz, 2005). Both acute (e.g., chest tightness, hacking cough, rhinorrhea) and delayed (e.g., chronic bronchitis, airway hyperreactvitiy, lung fibrosis and bronchopneumonia) effects have been reported after human exposure to SM (Balali-Mood and Hefazi, 2006; Ghanei et al., 2008).

Abbreviations: SM, sulfur mustard; BAL, bronchoalveolar lavage; COX-2, cyclooxygenase-2; iNOS, inducible nitric oxide synthase; TNF $\alpha$, tumor necrosis factor- $\alpha$; HO-1, hemeoxygenase-1; SP-D, surfactant protein-D; SOD, superoxide dismutase; PARP-1, poly-ADP-ribose polymerase-1; CEES, 2-chloroethyl ethyl sulfide; ARDS, acute respiratory distress syndrome; COPD, chronic obstructive pulmonary disease.

* Corresponding author. Department of Pharmacology and Toxicology, Ernest Mario School of Pharmacy, Rutgers University, 160 Frelinghuysen Road, Piscataway, NJ 088548020, USA.

E-mail address: laskin@eohsi.rutgers.edu (D.L. Laskin).
Toxicity is attributed to the lipophilic nature of SM which allows it to rapidly penetrate target tissues and alkylate proteins, lipids and nucleic acids resulting in DNA damage and cytotoxicity (Papirmeister et al., 1991). Currently, there are no effective therapies for mitigating the effects of SM on the lung. Towards this goal, animal models have been developed to identify mechanistic pathways leading to tissue injury.

Both experimental and human exposure data suggest an involvement of inflammatory cells and mediators in SM-induced lung injury. Thus, following exposure of rodents or pigs to SM by inhalation or intratracheal instillation, inflammatory cells are observed in the upper and lower respiratory track which persist for weeks to months (Calvet et al., 1999; Anderson et al., 2000, 2006, 2009; Kumar et al., 2001; Fairhall et al., 2008; Allon et al., 2009). Similarly, in humans, increased numbers of neutrophils and eosinophils are evident in the lung even a decade after exposure (Beheshti et al., 2006; Rowell et al., 2009). The specific role that these inflammatory cells play in SM-induced toxicity has not been elucidated. In other models of lung injury, inflammatory mediators released by macrophages have been shown to be key in the pathogenesis of toxicity (Laskin et al., 2010a,b), and they may play a similar role in the pulmonary response to SM. This is supported by findings that administration of nonspecific anti-inflammatory agents 

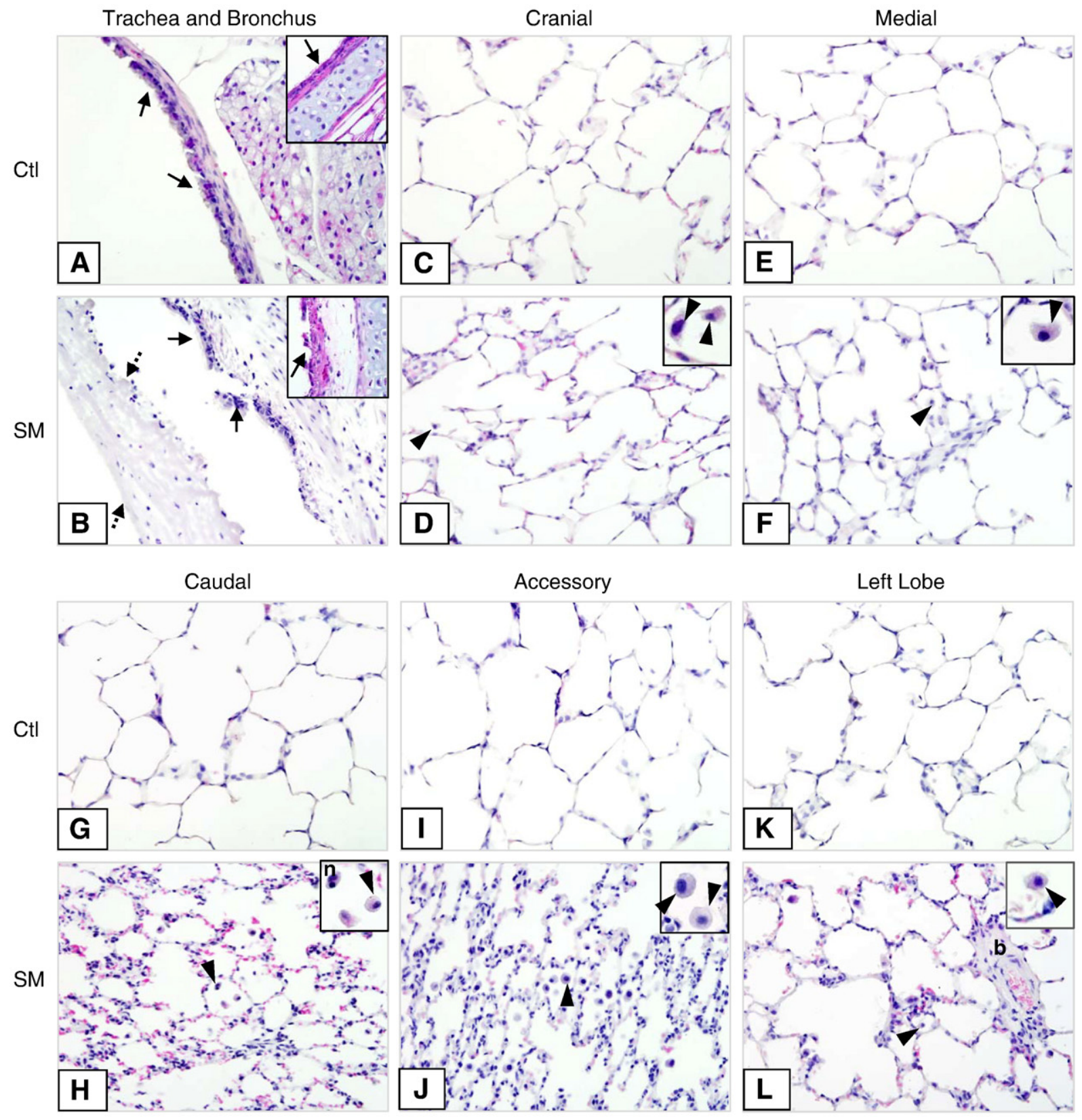

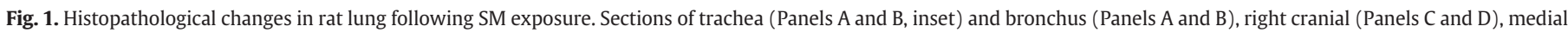

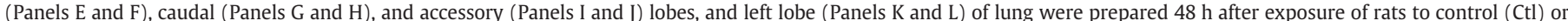

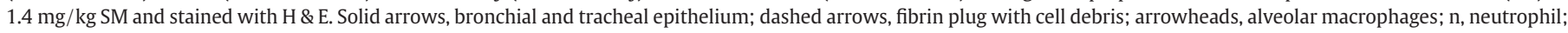
b, blood vessel. Original magnification 400×; Inset, 600×.

protects against lung injury induced by vesicants (Calvet et al., 1994a, 1996; Wigenstam et al., 2009).

The goal of the present study was to characterize pulmonary injury and inflammation in response to inhaled SM in a rodent model. Elucidating specific inflammatory mediators and cell types that accumulate in the lung in response to SM poisoning may be useful in identifying new targets for the development of therapeutic interventions.

\section{Materials and methods}

Animals and treatments. Male rats $\mathrm{Crl}: \mathrm{CD}(\mathrm{SD})(230-260 \mathrm{~g})$ were purchased from Charles River Laboratory (Wilmington, MA) and maintained in an AALAC approved animal care facility at the US Army Medical Research Institute of Chemical Defense (Aberdeen, MD).
Animals were housed individually on corncob bedding in polycarbonate shoe box cages (Lab Products, Maywood, NJ), and provided commercially certified rat chow and pyrogen-free water ad libitum. SM was obtained from the Research Division, Chemical Research, Development and Engineering Center (Aberdeen Proving Ground, MD) and diluted to $1.75,2.5$ or $3.5 \mathrm{mg} / \mathrm{ml}$ in absolute ethanol. Rats were exposed to $100 \mu \mathrm{l}$ of the appropriate SM solutions by intratracheal inhalation to achieve final doses of $0.7,1.0$ or $1.4 \mathrm{mg} / \mathrm{kg}$ as previously described (Anderson et al., 1996, 2000). Briefly, rats were anesthetized by intramuscular administration of ketamine $(80 \mathrm{mg} / \mathrm{kg})$ and xylazine $(10 \mathrm{mg} / \mathrm{kg})$, and intubated with a modified glass Pasteur pipette (approximately $6 \mathrm{~cm}$ long) using a laryngoscope to visualize the larynx, and PE90 tubing as a guide. Once in place, the endotracheal tube was secured with porous tape. SM, diluted in $100 \mu \mathrm{l}$ absolute ethanol to the desired dose or ethanol alone (control), was placed in a heated water jacketed glass 


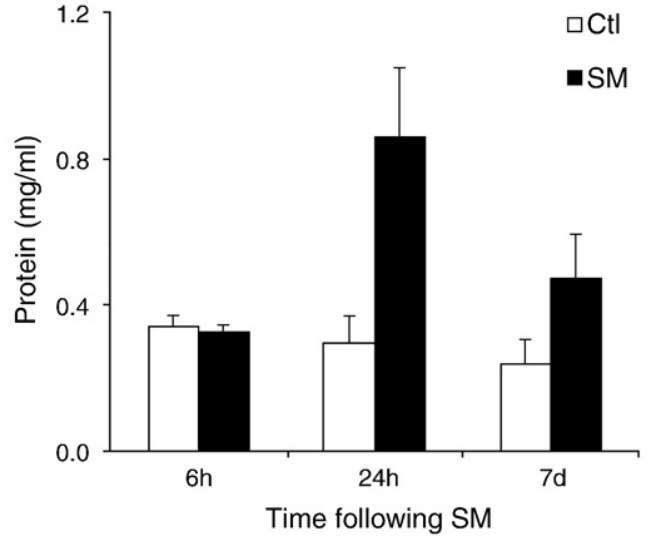

Fig. 2. Effects of SM on BAL protein levels. BAL, collected $6,24 \mathrm{~h}$ and 7 days after treatment of rats with control $(\mathrm{Ctl})$ or SM $(1 \mathrm{mg} / \mathrm{kg})$, was assayed for protein content. Each bar is the mean \pm SE $(n=3-5)$; *Significantly different $(p \leq 0.05)$ from control.

vapor generator, and spontaneously breathing rats were exposed for $50 \mathrm{~min}$. The endotracheal tube was then removed, and the rats returned to their cages. This passive exposure system included an inlet one-way respiratory check valve (Hans Rudolph, Inc., Kansas City, MO) to insure breathing through the vapor generator only.

Bronchoalveolar lavage (BAL) and tissue collection. Animals were deeply anesthetized and exsanguinated by clipping the vena cava. A 16-gauge needle was introduced into the trachea and secured using $3 / 0$ suture. The thoracic cavity was then opened to expose the trachea and lung. The left lung was lavaged three times with $3 \mathrm{ml}$ aliquots of sterile saline at room temperature (RT). The lavage fluid was pooled, centrifuged at $300 \times \mathrm{g}$ for $10 \mathrm{~min}$ and the supernatant collected and stored at $-80{ }^{\circ} \mathrm{C}$ until analyses. Immediately following lavage, the left lobe, along with the right cranial, medial, caudal, and accessory lobes of the lung were removed, snap frozen in liquid nitrogen and stored in $-80{ }^{\circ} \mathrm{C}$.

For histologic evaluation, the trachea, bronchus and lung lobes were removed and fixed in formalin. Sections ( $5 \mu \mathrm{m})$ were prepared, stained with hematoxylin and eosin, and examined by light microscopy. Images were acquired using DP controller software (Ver. 3.3.1.292) from Olympus Corporation (Center Valley, PA). The extent of inflammatory changes including macrophage and neutrophil localization, alterations in alveolar epithelial barriers and edema were assessed blindly by a veterinary pathologist (Sherritta Ridgely, D.V.M, Ph.D).

Preparation of tissue lysates. Frozen tissue samples (20-200 mg) were pulverized twice using an ice cold 316 stainless steel tissue pulverizer (Cole-Parmer, Vernon Hills, IL). The tissue was then lysed $(330 \mathrm{mg} / \mathrm{ml})$ in ice cold buffer ( $\mathrm{pH} 7.4)$ consisting of $20 \mathrm{mM}$ HEPES, $150 \mathrm{mM}$ sodium chloride, $1 \mathrm{mM}$ EGTA, $1.5 \mathrm{mM}$ magnesium chloride, $10 \%$ glycerol and $1 \%$ Triton X-100 and protease inhibitors ( $1 \mathrm{mM} \mathrm{PMSF}$, $10 \mathrm{mM}$ sodium pyrophosphate, $50 \mathrm{mM}$ sodium fluoride, $2 \mathrm{mM}$ sodium orthovanadate, $1 \mathrm{mM}$ lactacystin and $5 \%$ protease inhibitor cocktail). Samples were then centrifuged at $14,000 \times \mathrm{g}$ for $10 \mathrm{~min}$ at $4{ }^{\circ} \mathrm{C}$. Supernatants containing tissue lysates were frozen at $-80{ }^{\circ} \mathrm{C}$ until analyses.

Protein measurement. Total protein content in cell-free BAL and tissue lysates was quantified using a BCA protein assay kit (Pierce Biotechnologies Inc., Rockford, IL) following the manufacturer's directions with bovine serum albumin as the standard. All samples were assayed in triplicate.

Antibodies. Rabbit monoclonal anti-cleaved caspase-3, polyclonal anti-caspase-9, polyclonal anti-poly-ADP-ribose polymerase (PARP)-1, and polyclonal anti-LC3B antibody, and horse radish peroxidase (HRP)conjugated secondary goat anti-rabbit and horse anti-mouse antibodies were purchased from Cell Signaling Technology (Beverly, MA). Rabbit monoclonal anti-MMP-9, and polyclonal anti-COX-2 antibodies were from Abcam Inc. (Cambridge, MA). Mouse monoclonal anti-surfactant protein-D (SP-D) and rabbit polyclonal anti-inducible nitric oxide synthase (iNOS) antibodies were from Millipore Corp. (Billerica, MA). Rabbit polyclonal anti-hemeoxygenase (HO)-1, rabbit polyclonal $\mathrm{Cu}$ / $\mathrm{Zn}$-superoxide dismutase (SOD) and Mn-SOD antibodies were from Assay Designs (Ann Arbor, MI). Primary goat polyclonal anti-TNF $\alpha$ and secondary goat anti-rabbit antibodies were purchased from Santa Cruz Biotechnology (Santa Cruz, CA).

Western blot analysis. Proteins (10-100 $\mu \mathrm{g})$ were fractionated on $15 \%$ SDS polyacrylamide or 4-12\% Novex Bis-Tris gels (Invitrogen, San Diego, CA) and then transferred onto nitrocellulose membranes. Nonspecific binding was blocked by incubation of the blots with $5 \%$ non-fat dry milk in Tris-buffered saline/Tween-20 (20 mM Tris Base, pH 7.6, $137 \mathrm{mM}$ sodium chloride, and $0.1 \%$ Tween 20 ) for $1 \mathrm{~h}$ at room temperature (RT). The blots were incubated overnight at $4{ }^{\circ} \mathrm{C}$ with primary antibodies (1:500 to 1:1000) in Tris-buffered saline/Tween-20, washed three times, and then incubated for $1 \mathrm{~h}$ at RT with HRPconjugated secondary antibody $(1: 2000-1: 20,000)$, diluted in Trisbuffered saline/Tween-20. Immunoreactive bands were visualized using an ECL detection system (GE Healthcare Biosciences, Piscataway, $\mathrm{NJ}$ ). In some experiments membranes were stripped using Restore Western Blot Stripping Buffer (Thermo Scientific, Rockford, IL) and reprobed with different antibodies. Representative gels were analyzed by densitometry using Quantity One software and ChemiDoc-XRS blot imager (Bio-Rad Laboratories, Hercules, CA).

Immunohistochemistry. Paraffin sections (5-6 $\mu \mathrm{m})$ from control and SM treated animals were deparaffinized and endogenous peroxidase quenched using 3\% hydrogen peroxide diluted in methanol. Antigen retrieval was performed by boiling the specimens for $10 \mathrm{~min}$ in $10 \mathrm{mM}$ sodium citrate buffer ( $\mathrm{pH}$ 6.0) containing $0.05 \%$ Tween-20. To block nonspecific binding, sections were incubated for $1 \mathrm{~h}$ at RT in blocking buffer (Tris-buffered saline/Tween 20 containing goat or horse serum). Sections were then incubated overnight at $4{ }^{\circ} \mathrm{C}$ in a humidified chamber with primary antibody diluted in blocking buffer, followed by incubation at RT for 30 min with biotinylated secondary antibody (Vectastain Elite ABC kit, Vector Labs, Burlingame, CA). Binding was visualized using an avidin-biotyinylated enzyme complex (Vectastain Elite $A B C$ kit) with 3, 3'-diaminobenzidine (DAB) as the substrate (Vector Labs, Burlingame, CA).

Zymography. All reagents and gels were purchased from Invitrogen (Carlsbad, CA) and used according to the manufacturer's directions. Briefly, $10 \mu \mathrm{g}$ of BAL or tissue lysate proteins were mixed with zymogram sample buffer (Bio-Rad Labs, Hercules, CA) and subjected to electrophoresis on Novex $10 \%$ Zymogram gels containing $0.1 \%$ gelatin as substrate. The gels were then incubated with gentle shaking at RT in $1 \times$ Novex Zymogram Renaturing buffer for 30 min followed by $30 \mathrm{~min}$ equilibration and incubation in $1 \times$ Novex Zymogram Developing buffer at $37^{\circ} \mathrm{C}$ overnight. The gels were stained with SimplyBlue SafeStain (Invitrogen, Carlsbad) by microwaving for $1 \mathrm{~min}$ followed by washing in ultra purified MilliQ water at RT. Gelatinase ( $92 \mathrm{kDa}$ ) activity appeared as clear a band on the gel.

Transmission electron microscopy (TEM). Frozen lung specimens were fixed by immersion in 3\% glutaraldehyde in $0.2 \mathrm{M}$ sodium cacodylate buffer $\mathrm{pH} 7.3$ for $2 \mathrm{~h}$. Specimens were washed in $0.2 \mathrm{M}$ sodium cacodylate buffer $\mathrm{pH} 7.3$ for $10 \mathrm{~min}$, postfixed in $1 \%$ osmium tetroxide in $0.2 \mathrm{M}$ sodium cacodylate buffer for $1 \mathrm{~h}$ and then washed and dehydrated stepwise in graded ethanol. Samples were then embedded in pure EPON A and B mixture with DMP-30. One micron 

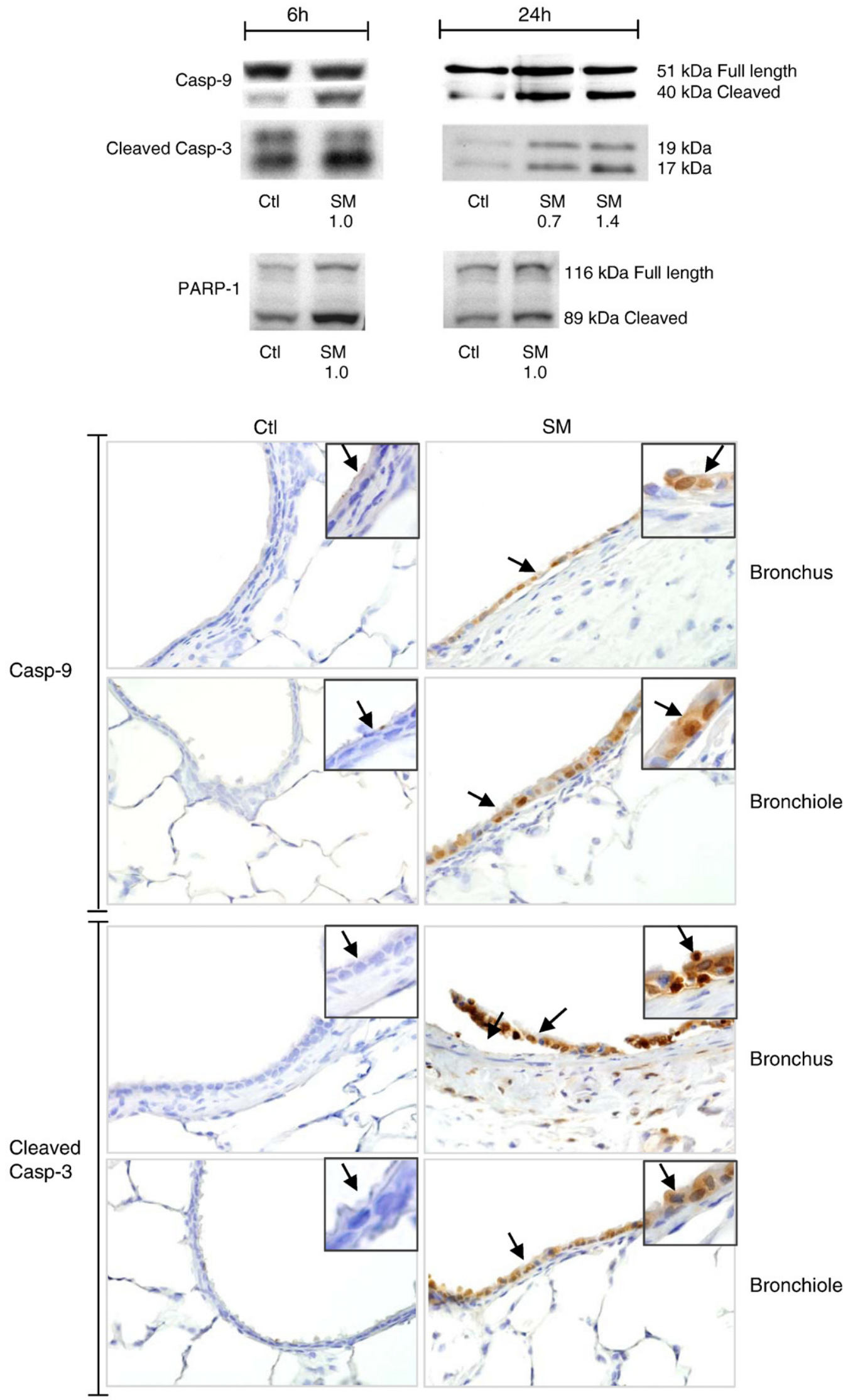

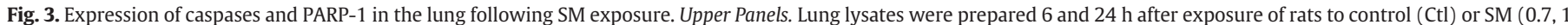

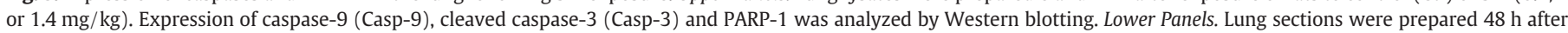

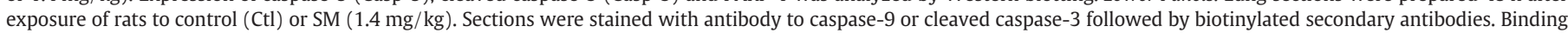
was visualized using a Vectastain kit. Arrows indicate bronchiolar and bronchial epithelial cells. Original magnification $600 \times$; Inset, $1000 \times$. 


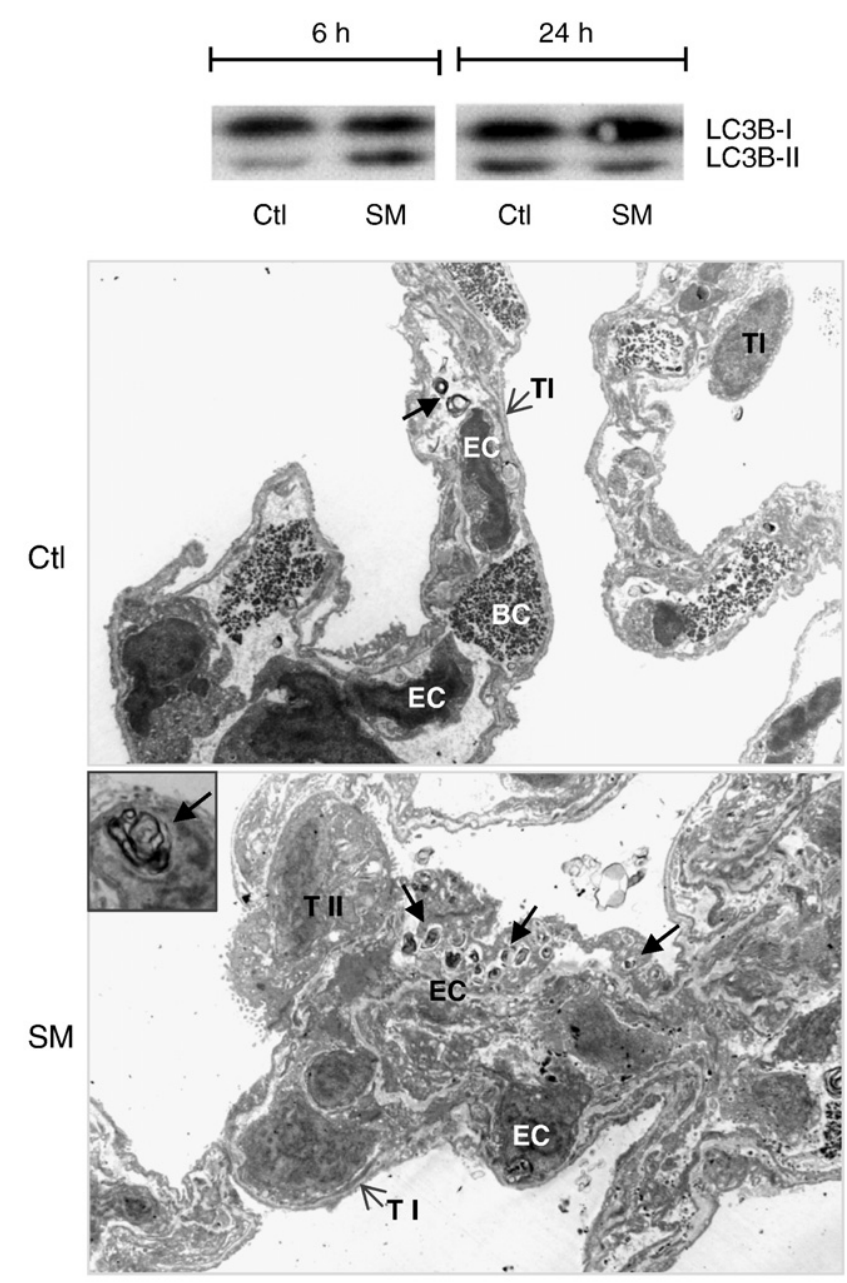

Fig. 4. SM induces autophagy in the lung. Upper Panel. Lung lysates were prepared 6 and $24 \mathrm{~h}$ after exposure of rats to control (Ctl) or SM $(1.4 \mathrm{mg} / \mathrm{kg})$. Expression of LC3BI and LC3BII was analyzed by Western blotting. Lower Panel. TEM of lungs prepared $6 \mathrm{~h}$ after treatment of rats with control $(\mathrm{Ctl})$ or $\mathrm{SM}(1 \mathrm{mg} / \mathrm{kg})$. Inset, autophagosome; blood capillary (BC); type I cell (TI); endothelial cell (EC); type II cell (TII); solid arrows, autophagosomes.

plastic sections were cut and stained with methylene blue azure II and examined by light microscopy. Representative areas were then chosen for ultrathin sectioning. The sections were stained with uranyl acetate and lead citrate and examined using a Hitachi H7650 instrument linked to an SIA digital camera (Scientific Instruments and Applications, Duluth, GA) controlled by Maxim CCD software.

Statistical analysis. Data were analyzed using two-way ANOVA or unpaired $t$-test (unequal variances). A $p$-value of $\leq 0.05$ was considered statistically significant.

\section{Results}

\section{Effects of SM on lung histology and BAL protein}

Histological changes in the trachea, the bronchi and each of the lobes of the lung including the right cranial, medial, caudal, and accessory lobes, as well as the left lobe were apparent as early as $6 \mathrm{~h}$ after exposure of rats to SM, a response that persisted for at least $48 \mathrm{~h}$ (Fig. 1 and not shown). At all post exposure times examined (6, 24 and $48 \mathrm{~h}$ ), extensive focal attenuation of tracheal epithelial cells, characterized by detachment of epithelium from the mucosa and loss of cilia was noted (Fig. 1, panels A and B insets, and not shown). Focal ulceration of tracheal mucosa was associated with luminal accumu- lation of fibrin entrapping cell debris and small numbers of neutrophils. The submucosa contained apoptotic nuclear debris that was not associated with inflammatory cellular infiltrates. After exposure to SM, but not control, the epithelium of the bronchus showed evidence of focal ulceration, luminal fibrin plug entrapping of low to moderate numbers of necrotic inflammatory cells and bronchial epithelial cells (Fig. 1, panels A and B). Patchy mild thickening of alveolar septa was also visible, characterized by increased numbers of mononuclear cells, neutrophils and macrophages in the right and left lobes of the lung (Fig. 1, panels C-L). This was most prominent in right caudal and accessory lobes, and the left lobe. Mild to moderate perivascular edema was also frequently noted with perivascular exudation of neutrophils and macrophages (Fig. 1, panel L). These findings suggested that SM caused disruption of the alveolar-epithelial barrier. To evaluate this, we measured protein accumulation in BAL, a marker of alveolar-epithelial damage (Bhalla, 1999). Low levels of protein were detected in BAL from control animals (Fig. 2). Treatment of rats with SM caused a 2-3 fold increase in BAL protein concentration which was evident $24 \mathrm{~h}$ post exposure. By 7 days, protein levels had returned to baseline control.

\section{SM induces apoptosis and autophagy in the lung}

In further studies we determined if lung injury induced by SM involved apoptosis. Initially to assess apoptosis, we analyzed expression of caspase-9, an initiator caspase activated following damage to mitochondrial membranes (Kumar, 2007). Both intact full length caspase-9 (51 kDa) and lower levels of cleaved caspase-9 (40 kDa) were evident in control lungs (Fig. 3, upper panel). Whereas expression of intact caspase- 9 remained relatively constant following exposure of rats to SM, expression of activated cleaved caspase- 9 increased; this was observed at 6 and $24 \mathrm{~h}$ post treatment at all doses of SM tested. We also analyzed expression of activated caspase-3, a key effector enzyme of the apoptotic pathway (Kumar, 2007). Western blot analyses of lung tissue showed that cleaved caspase- 3 proteins with molecular weights of 17 and $19 \mathrm{kDa}$ were present in the lungs of control rats (Fig. 3, upper panel). Treatment of the animals with SM resulted in a significant increase in expression of these proteins. Whereas at $6 \mathrm{~h}$, the $17 \mathrm{kDa}$ fragment increased, at $24 \mathrm{~h}$ both the 17 and $19 \mathrm{kDa}$ proteins were upregulated. No major differences were noted between 0.7 and $1.4 \mathrm{mg} / \mathrm{kg}$ SM. Immunohistochemical analysis of lung sections confirmed that SM treatment of the animals resulted in upregulation of both caspase- 9 and cleaved caspase 3 in the epithelium of the bronchi and bronchioles (Fig. 3, lower panels). This was associated with epithelial cell shrinkage and nuclear condensation, two characteristic features of apoptosis (Torchinsky et al., 2010). This was most notable in epithelium that was detached from the basement membrane. After SM inhalation, low levels of caspase-3 were also evident in smooth muscle cells underlying the epithelium.

We next analyzed expression of the DNA repair enzyme, PARP-1, which is proteolytically inactivated by caspase-3 (Soldani and Scovassi, 2002). As shown in Fig. 3 (upper panel), low levels of intact (116 kDa) and cleaved ( $89 \mathrm{kDa}$ ) PARP-1 were present in lungs of control animals. SM exposure caused an increase in cleaved PARP-1 which was evident at $6 \mathrm{~h}$, and persisted for $24 \mathrm{~h}$, although at lower levels. At $6 \mathrm{~h}$, a small increase in expression of the intact protein was also noted.

Autophagy is a cellular stress-induced catabolic process that involves degradation of cytoplasmic contents in characteristic double-membrane vacuoles called autophagosomes (Virgin and Levine, 2009). To determine if SM intoxication involved autophagy, we analyzed expression of LC3B, a mammalian homolog of the yeast autophagy gene Atg8 which associates with the autophagosome membranes (Virgin and Levine, 2009). Both cytosolic LC3B-I, and membrane bound LC3B-II were detectable in control lungs (Fig. 4, upper panel). Treatment of rats with SM caused a transient increase in expression of membrane bound LC3B-II, which was observed $6 \mathrm{~h}$ post exposure; by $24 \mathrm{~h}$, expression of this protein was similar in lungs 

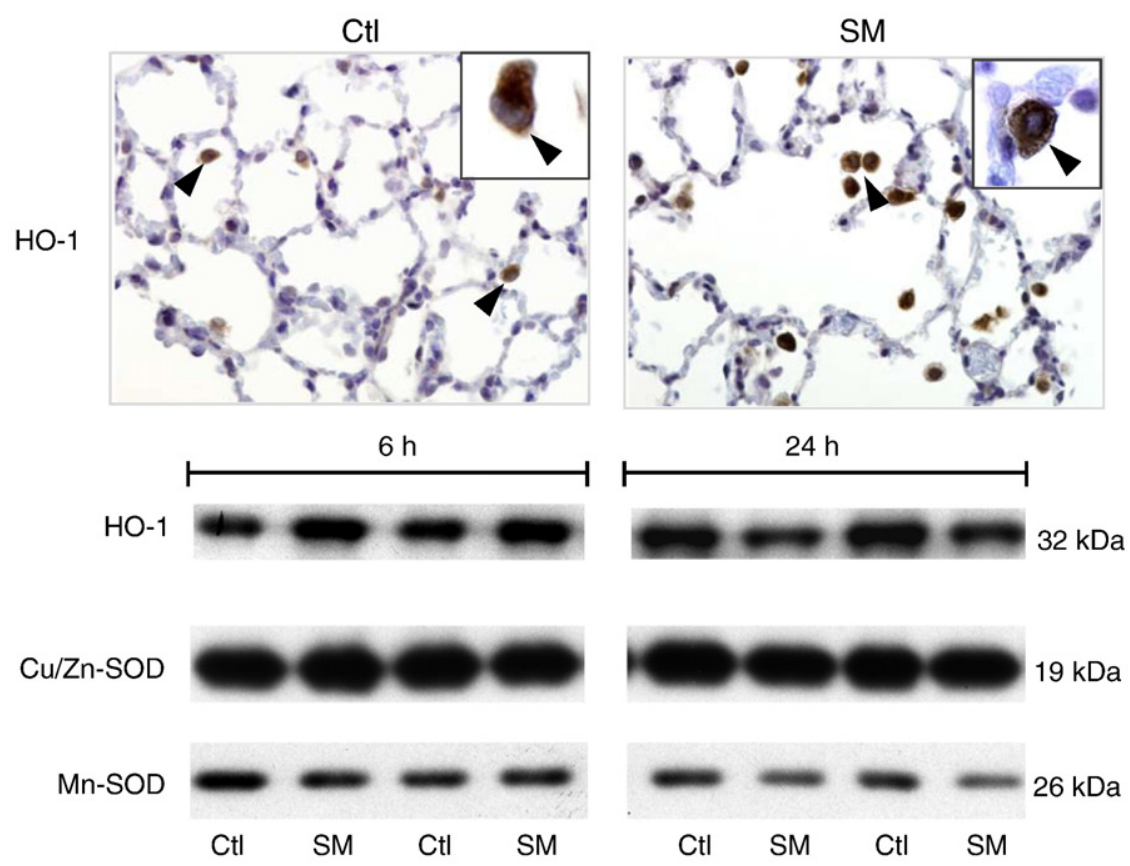

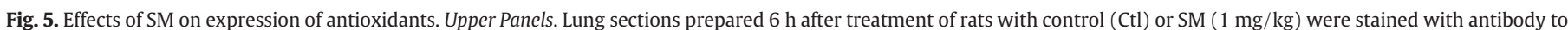

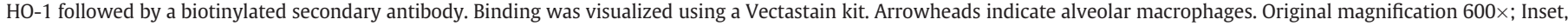

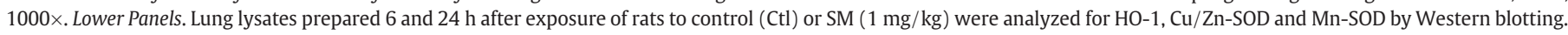

of control and SM treated animals. To confirm SM-induced autophagy, lung sections were examined by transmission electron microscopy. Low numbers of autophagosomes were evident in lungs from control rats (Fig. 4, lower panel). Treatment of the animals with SM resulted in a significant increase in the number of autophagosomes which were mainly detected in endothelial cells.

\section{Effect of SM on antioxidant expression}

In our next series of studies we analyzed the effects of SM on expression of enzymes important in protecting the lung from oxidative stress including HO-1 and SOD (Reddy, 2008). Immunostaining of lung sections showed low levels of HO-1 in macrophages from control animals (Fig. 5, upper panels). SM exposure resulted in an increase in both the intensity of HO-1 expression, and the number of cells expressing this antioxidant. Western blot analysis demonstrated that the effects of SM on HO-1 expression were transient; thus by 24 h post exposure, HO-1 expression was decreased to levels below control (Fig. 5 , lower panels). In contrast to HO-1, SM exposure had no major effects on expression of $\mathrm{Cu} / \mathrm{Zn}-\mathrm{SOD}$ or Mn-SOD.

\section{Effect of SM on expression of inflammatory proteins in the lung}

TNF $\alpha$ is a pro-inflammatory cytokine implicated in pulmonary pathophysiology (Mukhopadhyay et al., 2006). Treatment of rats with SM resulted in upregulation of TNF $\alpha$ expression in alveolar macrophages which was most pronounced $48 \mathrm{~h}$ post exposure (Fig. 6, upper panel). At this time, low levels of TNF $\alpha$ staining were also evident in alveolar epithelial cells. In contrast, no TNF $\alpha$ immunoreactivity was detected in lungs of control animals. iNOS is an inducible enzyme mediating the generation of nitric oxide from L-arginine (Laskin et al., 2010b). Low level staining of iNOS was noted in alveolar macrophages and epithelial cells in lungs of control animals (Fig. 6, middle panel). Following SM inhalation, expression of iNOS increased in these cells. We also analyzed the effects of SM on expression of COX-2, an arachidonic acid metabolizing enzyme important in generating prostaglandins. Western blot analysis revealed low constitutive levels of COX-2 in lungs of control animals (Fig. 6, lower panel). Exposure of rats to SM resulted in increased COX-2 expression which was evident at 24 and $48 \mathrm{~h}$. After 48 h, COX-2 was predominantly localized in alveolar macrophages. The effects of SM on COX-2 expression were dose related in the range of $0.7-1.4 \mathrm{mg} / \mathrm{kg}$.

MMPs are matrix degrading zinc endopeptidases upregulated during pulmonary inflammatory responses (Corbel et al., 2002). Western blot analysis of lung tissue from control animals revealed the presence of MMP-9 protein, most likely due to the ethanol vehicle (Fig. 7, upper panels). MMP-9 expression increased significantly following SM treatment of rats. This was evident at $6 \mathrm{~h}$ and persisted for at least $24 \mathrm{~h}$ after exposure. The effects of SM on MMP-9 expression were dosedependent reaching a maximum at $1.4 \mathrm{mg} / \mathrm{kg}$. Immunohistochemical analysis of the lung tissue indicated that MMP-9 was up-regulated in the bronchiolar epithelium and alveolar macrophages (Fig. 7, lower panels). MMP-9 was also detected in BAL beginning at $6 \mathrm{~h}$ and persisting for at least 7 days after SM exposure (Fig. 7, upper panels). SM induced increases in MMP-9 expression after SM exposure correlated with increases in $92 \mathrm{kDa}$ gelatinase activity in both tissue and BAL, as measured by zymography. In the tissue, greater gelatinase activity was observed at the highest dose of SM and $24 \mathrm{~h}$ after exposure, while in BAL, gelatinase activity remained relatively constant between $6 \mathrm{~h}$ and 7 days post SM exposure. In contrast to MMP-9, MMP-2 expression in lung and BAL was unaffected by SM (data not shown).

SP-D is a pulmonary collectin known to play a role in negatively regulating lung inflammation (Crouch, 2000). SP-D was constitutively expressed in lungs of control rats (Fig. 8, upper panel). Treatment of the animals with SM caused a time-dependent decrease in SP-D in the lung which was most pronounced at $24 \mathrm{~h}$. At this time, no major differences were noted between the different doses of SM tested. Immunohistochemistry revealed that in lungs of control animals, SP-D was mainly expressed in bronchiolar epithelium and type II alveolar epithelial cells (Fig. 8, lower panels); alveolar macrophages either stained weakly or were negative for SPD. Whereas exposure of rats to SM resulted in a significant decrease in SP-D expression in bronchiolar epithelium and type II cells, a marked increase in this protein was noted in alveolar macrophages. SP-D was also detectable in BAL from control animals. While SM had no major effects on BAL SP-D levels after 6 or $24 \mathrm{~h}$, a significant increase in levels of SP-D were observed 7 days post-exposure. 


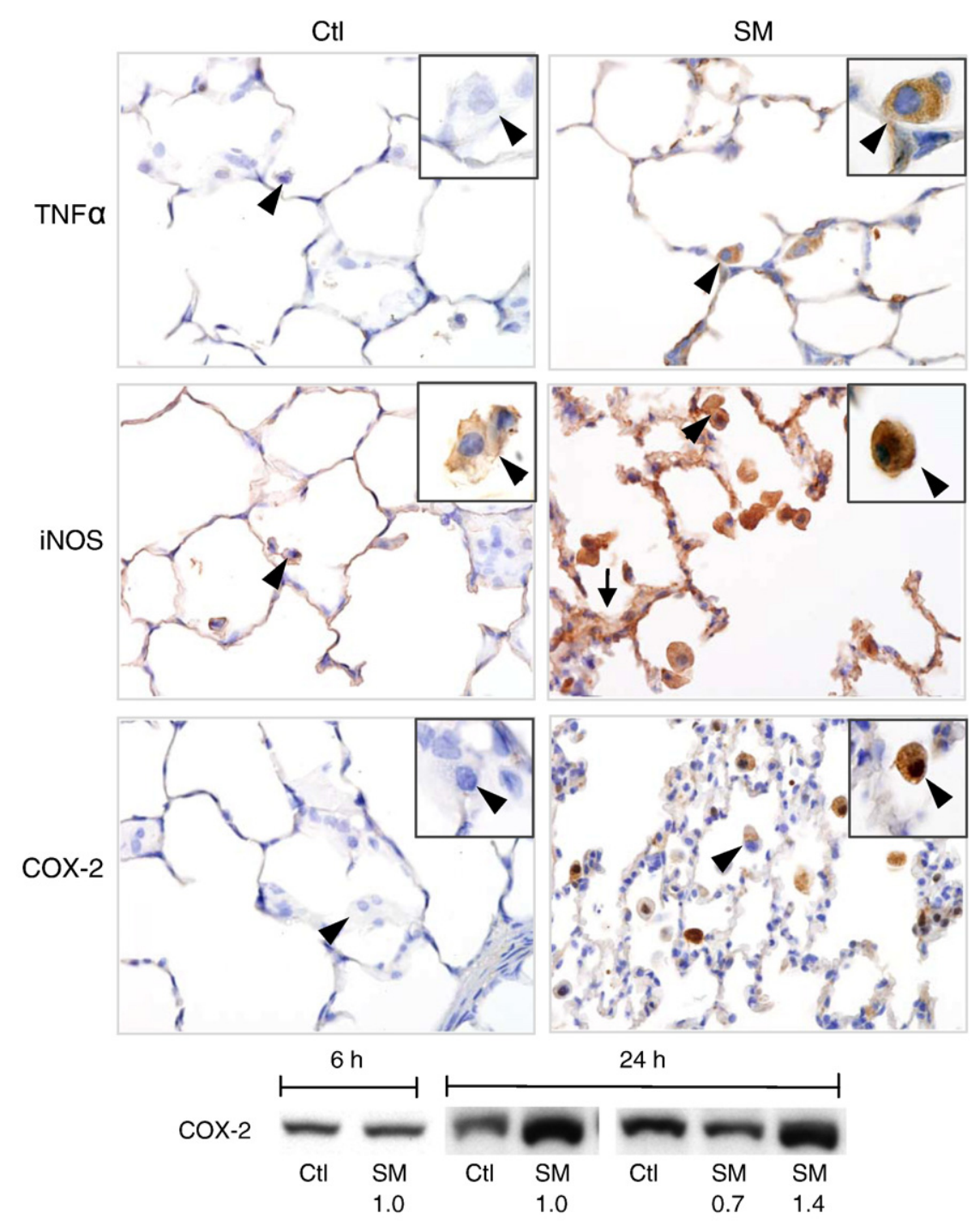

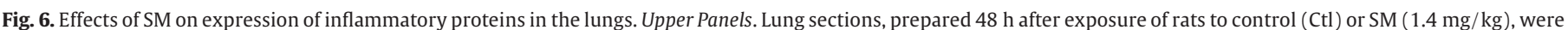

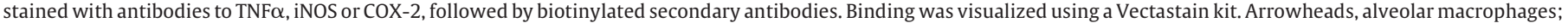

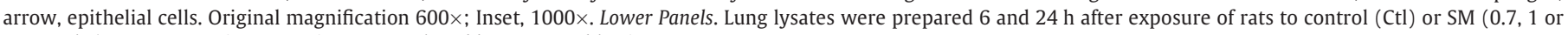
$1.4 \mathrm{mg} / \mathrm{kg}$ ). COX-2 protein expression was analyzed by Western blotting.

\section{Discussion}

Accumulating evidence suggests that mediators released from inflammatory cells contribute to lung injury induced by diverse pulmonary toxicants (Laskin et al., 2010a). The role of inflammatory mediators in SM-induced pulmonary injury is unknown. Findings that anti-inflammatory steroids, such as betamethasone inhibit SMinduced airway injury and hyperresponsivness, suggest that phagocytic leukocytes are involved in the pathogenic response (Calvet et al., 1994a, 1996). This is supported by reports that inhaled corticosteroids improve pulmonary function in patients with chronic bronchiolitis as a result of SM inhalation (Ghanei and Harandi, 2007). In the present studies we characterized pulmonary injury and inflammatory responses to inhaled SM in a rodent model. Identification of the specific cytotoxic/proinflammatory mediators involved in SM-induced lung injury may help in the development of agents to mitigate the toxicity of this vesicant.

Exposure of rats to inhaled SM resulted in rapid pulmonary toxicity. Thus, within $6 \mathrm{~h}$ of exposure, histopathologic changes were noted in the upper airways; these included detachment of tracheal and bronchial epithelial lining from the basement membrane, deposits of fibrin containing cellular debris in the airway lumen, and edema of the submucosal lining. Similar alterations in the airway epithelium have been described in the lungs of rodents exposed to SM (Calvet et al., 1994b, 1996, 1999; Anderson et al., 1996; Guignabert et al., 2005). Inhaled SM also caused lower airway effects including thickening of alveolar septal walls and perivascular edema suggesting potential alterations in the integrity of alveolar epithelial lining. This was supported by our findings that BAL protein levels and cells (Anderson et al., 1996) increased significantly after exposure of rats to SM. These data are consistent with previous reports of mustardinduced alveolar epithelial damage in rodents (Guignabert et al., 2005; McClintock et al., 2006). Structural alterations in the lung were accompanied by inflammatory cell infiltration into the airways and parenchyma, as assessed histologically, and by increased numbers of cells recovered in BAL (Calvet et al., 1999; Anderson et al., 2000). The majority of these inflammatory cells were macrophages, supporting the idea that phagocytic leukocytes are important in the pathogenic response to inhaled vesicants (Gao et al., 2010).

SM is a bifunctional alkylating agent that crosslinks DNA (Papirmemeister et al., 1991; Debiak et al., 2009). The outcome of the response to SM depends on the extent of alkylation and crosslinking. At high doses, alkylation may be extensive resulting in activation of initiator and effector caspases and induction of apoptosis (Debiak et al., 2009). The 


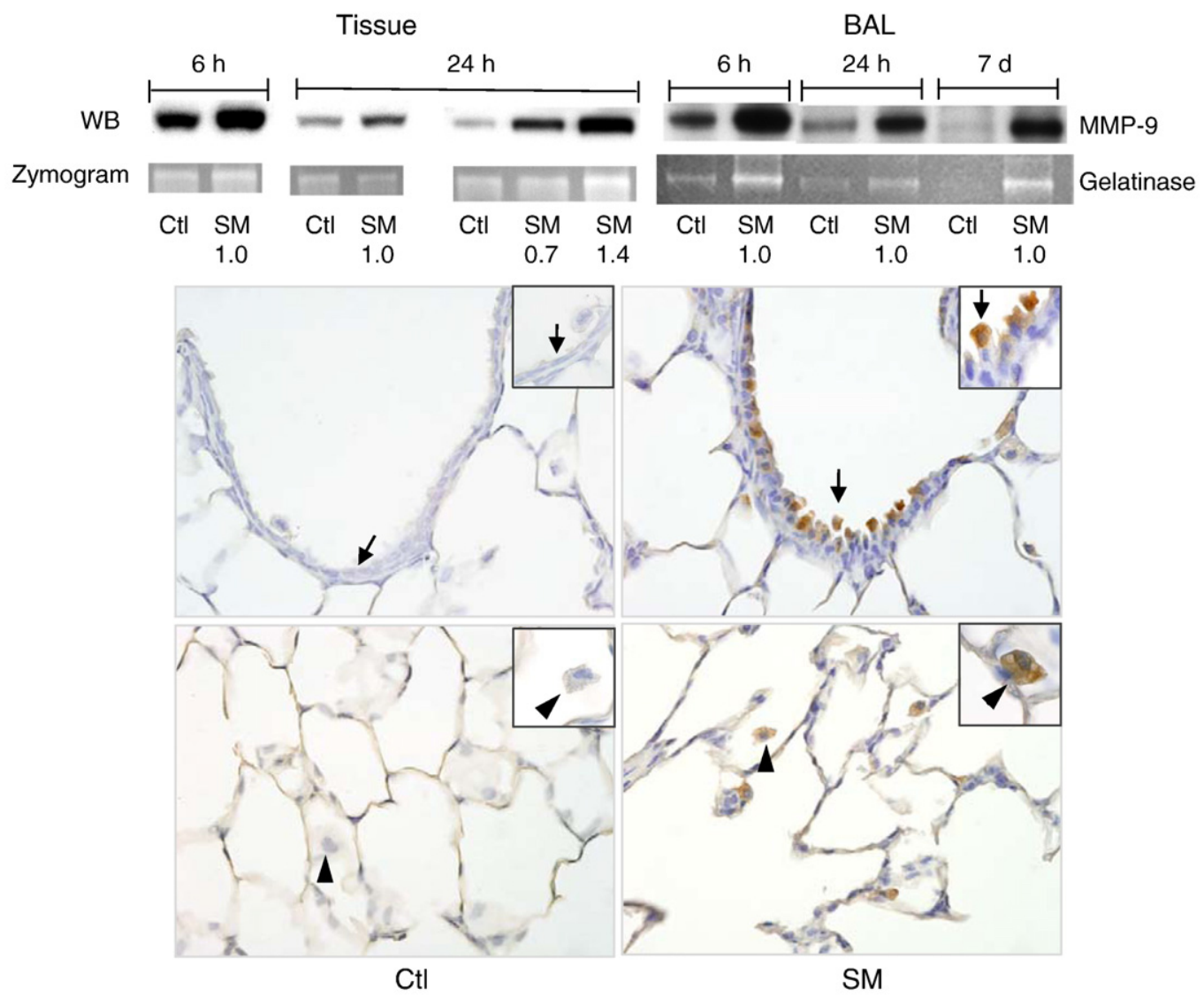

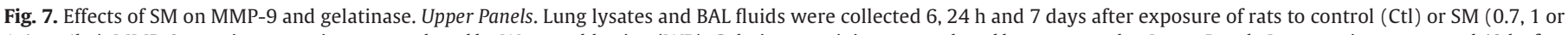

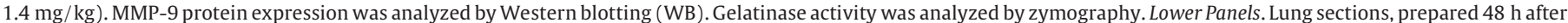

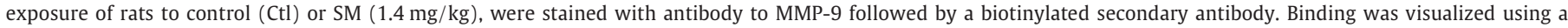
Vectastain kit. Arrows, bronchiolar epithelium; arrowheads, alveolar macrophages. Original magnification 600×; Inset, 1000×.

present studies demonstrate that inhaled SM induces alterations in bronchial epithelial cells that are characteristic of apoptosis including cell shrinkage and chromatin condensation. Interestingly, this was prominent in epithelium that was detached from the basement membrane. These findings are consistent with previous reports that SM induces cell detachment-dependent apoptosis or anoikis (Sourdeval et al., 2006). The mechanisms underlying epithelial detachment in the lung following SM exposure are unknown. In keratinocytes, SM has been reported to modify intermediate filaments that are required for maintaining connections between epithelial cells and basal lamina, and a similar process may occur in the lung (Dillman et al., 2003; Hess and FitzGerald, 2007; Mol et al., 2008).

A hallmark of apoptosis is sequential activation of cysteine proteases including caspase-9, which initiates apoptosis, and its downstream target, caspase-3, an executioner caspase (Cusimano et al., 2009). Western blot analyses of lung tissue showed that SM inhalation resulted in activation of both caspase- 9 and caspase- 3 . This was observed within $6 \mathrm{~h}$ of SM exposure and persisted for at least $24 \mathrm{~h}$. Immunohistochemical analysis of tissue sections revealed that the caspases were localized mainly in the bronchial epithelium. Similar increases in expression of activated caspases have been described in alveolar macrophages isolated from SM treated rats, and in bronchial/tracheal and small airway epithelial cells treated in vitro with SM (Sourdeval et al., 2006; Ray et al., 2008, 2010). These data provide additional support for a link between SM-induced lung injury and apoptosis.

PARP-1 is a nuclear repair enzyme activated following DNA damage (Debiak et al., 2009). Cleavage of PARP-1 by caspases into 89- and 24-kDa fragments is considered a feature of late apoptosis. Following SM inhalation, we found evidence of increased expression of both intact and cleaved PARP-1 in the lung. These data confirm that
SM induces DNA damage, and that this is linked to apoptosis (Kehe et al., 2009). The role of PARP-1 in the toxicity of vesicants has received considerable attention (Debiak et al., 2009). This enzyme mediates the repair of single stranded DNA damage and is thought to be key in maintaining survival and genomic integrity under genotoxic stress. Finding that PARP-1 is rapidly inactivated in the lung following SM exposure suggests a potential mechanism contributing to tissue injury induced by this vesicant.

Autophagy is a tightly regulated catabolic process involving intracellular self-degradation that has been shown to play a role in normal cell growth, development and homeostasis. However, under conditions of oxidative stress, autophagy is thought to represent an alternative form of non-apoptotic cell death (Uchiyama et al., 2008). Transmission electron microscopy revealed the presence of autophagosomes in the lungs of rats treated with SM. These were evident as early as $6 \mathrm{~h}$ after treatment and persisted for at least $48 \mathrm{~h}$. This was correlated with increased expression of LC3B-II, a lipidated form of LC3B-I protein, which is known to associate with autophagosome membranes (Virgin and Levine, 2009). Long term consequences of exposure to SM include the development of chronic obstructive pulmonary disease (COPD). Markers of autophagy have been noted in the lungs of patients in the early stages of the development of this disease (Chen et al., 2008). The fact that there is evidence of autophagy in lungs of animals shortly after exposure to SM suggests that this cytotoxic mechanism may be important in the pathogenesis of chronic lung diseases in exposed subjects. This is supported by findings that exposure to cigarette smoke, which is also a causative agent for COPD, induces autophagy in lung epithelial cells (Chen et al., 2008).

A characteristic response of cells and tissues to oxidative stress is upregulation of HO-1, a phase II enzyme with antioxidant and 
Tissue

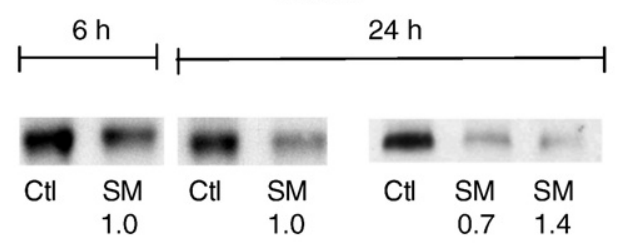

BAL

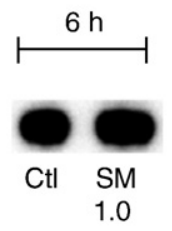

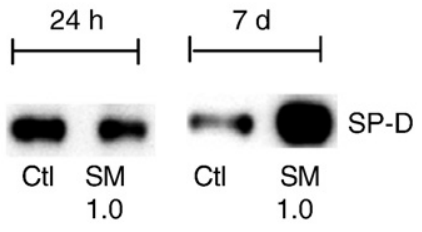
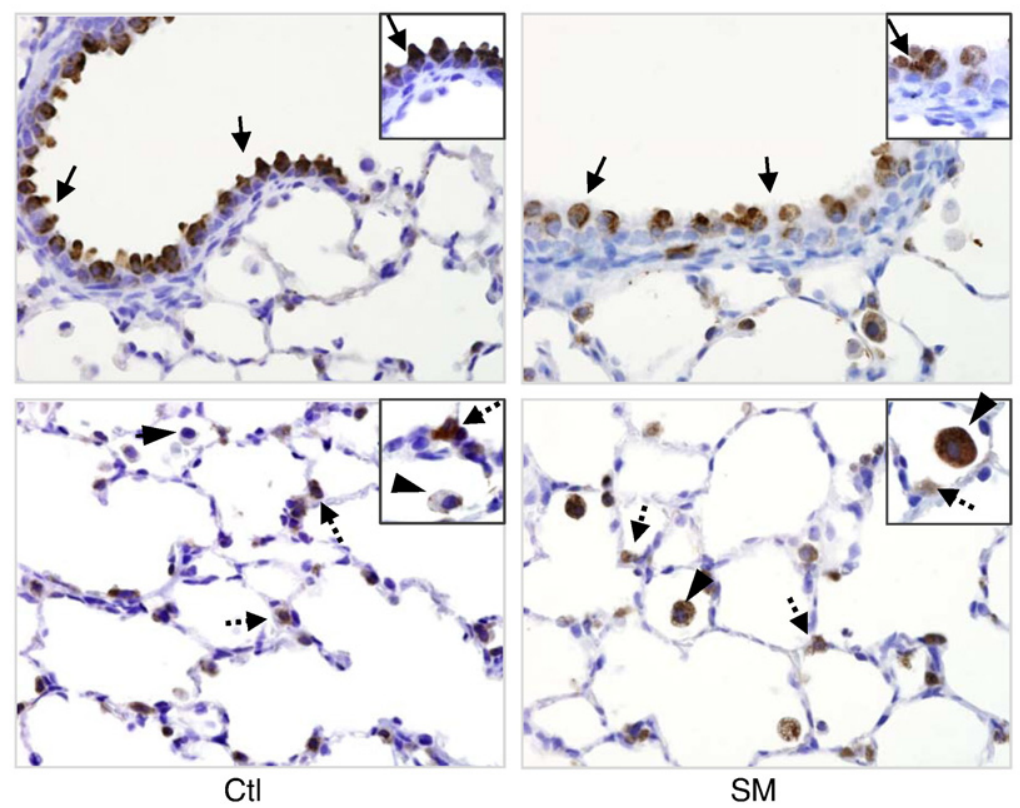

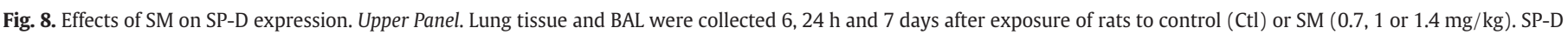

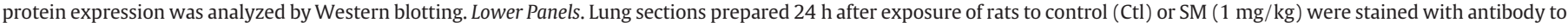

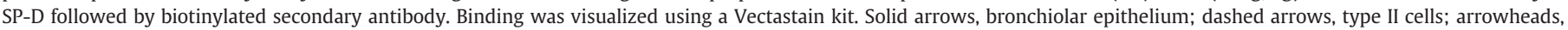
alveolar macrophages. Original magnification 600×; Inset, 1000×.

antiapoptotic activity. Following SM inhalation, a rapid and transient induction of HO-1 protein was observed in the lung, confirming that SM induced toxicity is associated with oxidative stress (Korkmaz et al., 2006). The finding that HO-1 expression was predominantly localized in alveolar macrophages, suggests that these cells are a major source of cytotoxic oxidants. Interestingly, upregulation of HO-1 was transient and by $24 \mathrm{~h}$ was below control levels. A similar biphasic effect on HO-1 has been described after exposure of macrophages to cigarette smoke (Goven et al., 2009). The mechanism underlying this effect is unknown and may be due to impaired transcriptional activation of the HO- 1 gene (Goven et al., 2009). In contrast to its effects on HO-1, SM inhalation had no major effect on expression of $\mathrm{Mn}-\mathrm{SOD}$ or $\mathrm{Cu} / \mathrm{Zn}-\mathrm{SOD}$. These results were surprising since intratracheal instillation of liposomes containing SOD and catalase has been reported to ameliorate vesicant-induced lung injury (McClintock et al., 2006; Mukherjee et al., 2009). Moreover, a catalytic antioxidant possessing SOD and catalase activity was effective in reducing inflammation and oxidative stress following inhalation of 2-chloroethyl ethyl sulfide (CEES), a half mustard analog of SM (O'Neill et al., 2010). It may be that SM induces changes in pulmonary expression of EC-SOD, an extracellular form of SOD, which is considered to be prominent in antioxidant defense of the lung, and this remains to be determined (Oberley-Deegan et al., 2009).

Nitric oxide is produced by macrophages via an inducible form of the enzyme, nitric oxide synthase. Once generated, nitric oxide readily reacts with superoxide anion forming peroxynitrite, a long-lived cytotoxic oxidant. Evidence suggests that these reactive nitrogen species contribute to oxidative stress and tissue damage induced by diverse pulmonary toxicants (Laskin et al., 2010b). The present studies demonstrate that iNOS is markedly upregulated in macrophages and lung epithelial cells after SM exposure. These findings are consistent with previous reports that SM upregulates iNOS expression and nitric oxide production in cultured airway epithelial cells, and a monocytic cell line (Gao et al., 2008, 2010). The observation that SM-induced cytotoxicity is ameliorated by blocking or reducing production of reactive nitrogen species provides support for their role in the pathogenesis of vesicant-induced tissue injury (Gao et al., 2008). We also found that COX-2, which mediates the production of proinflammatory eicosanoids, was upregulated in the lung after SM treatment of rats. In contrast to iNOS, this was mainly localized in alveolar macrophages. An involvement of COX-2 in SM-induced skin toxicity is well documented. Thus, COX-2 is rapidly upregulated in the skin following dermal exposure to SM; additionally, indomethacin, a nonspecific COX inhibitor ameliorates SM-induced dermal inflammation (Yourick et al., 1995; Babin et al., 2000; Casillas et al., 2000; Nyska et al., 2001). More recent studies have also demonstrated that COX-2 knockout mice or mice pretreated with the selective COX-2 inhibitor, celecoxib are protected from SM-induced skin injury (Wormser et al., 2004). It remains to be determined whether comparable protective effects against SM poisoning are observed in the lung.

SM-induced oxidative stress is thought to be a primary event triggering inflammation. Early response proinflammatory cytokines such as TNF $\alpha$ are rapidly generated in tissues in response to oxidative stress. It has been suggested that initiation of the free-radicalmediated TNF $\alpha$ cascade is a major pathway in vesicant-induced lung injury (Chatterjee et al., 2003; Mukhopadhyay et al., 2006). We found that SM exposure resulted in increased expression of TNF $\alpha$ in the lung, which was evident in macrophages and alveolar epithelial cells, $48 \mathrm{~h}$ post exposure. In contrast, Chatterjee et al. (2003) reported that 
increases in TNF $\alpha$ in the lung were transient, appearing within $1 \mathrm{~h}$ of exposure of animals to the half mustard, CEES, and returning to control levels by $24 \mathrm{~h}$. Differences between these results and ours may be due to unique responses of different species (e.g., rats versus guinea pigs) to vesicants, the method of vesicant exposure, and/or distinct cytotoxic properties of SM and CEES. The precise role of TNF $\alpha$ in SM-induced lung injury is unknown. TNF $\alpha$ binds to receptors on target cells such as macrophages resulting in activation of biochemical signaling molecules like NFKB and AP-1, transcription factors regulating expression of inflammatory genes including iNOS and COX-2, and this may be important in its pathogenic actions. Recent findings that TNFR1 knockout mice are protected from lung injury induced by CEES, suggest a potential target for therapy to mitigate vesicant-induced inflammatory mediator production, and potentially, pulmonary toxicity (Sunil et al., 2009).

TNF $\alpha$ is also known to upregulate expression of MMPs which degrade extracellular matrix components and have been implicated in lung toxicity (Ohbayashi, 2002). Evidence suggests an important role of MMPs in the toxicity of SM, not only in the lung, but also in the skin and eye (Shakarjian et al., 2010). The present studies demonstrate that SM caused a dose- and time-dependent increase in expression of MMP-9 in the lung which was mainly localized in bronchiolar epithelium and alveolar macrophages; MMP-9 protein and gelatinase activity were also upregulated in BAL following SM administration to rats. These findings are in accord with previous observations after exposure of rodents to SM (Calvet et al., 1999; Guignabert et al., 2005; Anderson et al., 2009). It is possible that MMP-9 plays a role in SM-induced detachment of epithelia and epithelial cell sloughing. This is supported by findings that MMP-9/92 kDa gelatinase B is present at epithelial detachment sites, that this is directly correlated with SM-induced alveolar epithelial injury, and that MMP inhibitors such as doxyclyline and illomastat ameliorate vesicant-induced respiratory lesions (Calvet et al., 1999; Guignabert et al., 2005; Anderson et al., 2009).

A question arises as to what controls inflammatory cell activity in the lung following SM-induced injury. Collectins, including SP-D, are soluble pattern recognition receptors belonging to the superfamily of collagen containing C-type lectins. These molecules are thought to be major regulators of innate immune responses in the lung (Chroneos et al., 2010). Whereas in its native form, SP-D possesses antiinflammatory activity, post-translational modification by reactive nitrogen species results in a change in SP-D to a pro-inflammatory protein (Guo et al., 2008). In the lung, SP-D is produced by type II epithelial cells, Clara cells, and submucosal glands in the pulmonary airways. Mice lacking SP-D show evidence of persistent pulmonary inflammation, including increases in macrophage numbers and size within the airways, increases in MMP activity, and enhanced oxidative-nitrosative stress (Atochina-Vasserman et al., 2007). We found that SM exposure resulted in a time-dependent decrease in native SP-D expression in bronchiolar epithelial cells which was directly correlated with inflammation and tissue injury. These results are consistent with reports that mustards damage type II cells and alter the surface tension of BAL, and suggest a potential mechanism leading to the development of acute respiratory distress syndrome in SM-exposed individuals (van Helden et al., 2004; Sinha Roy et al., 2005; Mukhopadhyay et al., 2008). Interestingly, SP-D staining increased in alveolar macrophages following SM exposure which was likely due to uptake of the protein by these phagocytic cells. Macrophages are a major source of reactive nitrogen species (Laskin et al., 2010b). S-nitrosylation of SP-D by macrophage-derived reactive nitrogen species may contribute to the proinflammatory environment in the lung following SM exposure. Administration of Curosurf surfactant, which contains SP-D, has been reported to reduce SM-induced mortality in guinea pigs (van Helden et al., 2004). These data suggest that SM-induced damage to lung surfactants such as SP-D may render the tissue more susceptible to oxidative stress, inflammation and injury.
In summary, the present studies demonstrate that inhalation exposure of rats to environmentally relevant doses of SM (Willems, 1989; Eisenmenger et al., 1991) induces oxidative stress, inflammation, and tissue injury, characterized by both apoptosis and autophagy. Although DNA and protein alkylation by SM are well established consequences of exposure, precisely how these alterations lead to pulmonary injury is unknown. Our findings that SM-induced acute lung injury is associated with increased proinflammatory activity of macrophages, autophagy in endothelial cells and anoikis in bronchiolar epithelium indicate that different lung cell populations respond distinctly to mustard gas inhalation. These data are novel and suggest that multifaceted approaches targeting different lung cell populations may be an effective therapeutic strategy for mitigating the toxicity of vesicants.

\section{Conflict of interest}

The authors declare that there are no conflicts of interest.

\section{Acknowledgments}

This work was supported by NIH Grants HL096426, AR055073, GM034310, ES004738, CA132624, and ES005022, and by the Defense Threat Reduction Agency-Joint Science and Technology Office, Medical S \& T Division.

\section{References}

Allon, N., Amir, A., Manisterski, E., Rabinovitz, I., Dachir, S., Kadar, T., 2009. Inhalation exposure to sulfur mustard in the guinea pig model: clinical, biochemical and histopathological characterization of respiratory injuries. Toxicol. Appl. Pharmacol. 241, 154-162.

Anderson, D.R., Yourick, J.J., Moeller, R.B., Petrali, J.P., Young, G.D., Byers, S.L., 1996. Pathological changes in rat lungs following acute sulfur mustard inhalation. Inhal. Toxicol. 8, 285-297.

Anderson, D.R., Byers, S.L., Vesely, K.R., 2000. Treatment of sulfur mustard (HD)-induced lung injury. J. Appl. Toxicol. 20, S129-S132.

Anderson, D.R., Holmes, W.W., Lee, R.B., Dalal, S.J., Hurst, C.G., Maliner, B.I., Newmark, J. Smith, W.J., 2006. Sulfur mustard-induced neutropenia: treatment with granulocyte colony-stimulating factor. Mil. Med. 171, 448-453.

Anderson, D.R., Taylor, S.L., Fetterer, D.P., Holmes, W.W., 2009. Evaluation of protease inhibitors and an antioxidant for treatment of sulfur mustard-induced toxic lung injury. Toxicology 263, 41-46.

Atochina-Vasserman, E.N., Beers, M.F., Kadire, H., Tomer, Y., Inch, A., Scott, P., Guo, C.J., Gow, A.J., 2007. Selective inhibition of inducible NO synthase activity in vivo reverses inflammatory abnormalities in surfactant protein D-deficient mice. J Immunol. 179, 8090-8097.

Babin, M.C., Ricketts, K., Skvorak, J.P., Gazaway, M., Mitcheltree, L.W., Casillas, R.P., 2000 Systemic administration of candidate antivesicants to protect against topically applied sulfur mustard in the mouse ear vesicant model (MEVM). J. Appl. Toxicol. 20, S141-S144.

Balali-Mood, M., Hefazi, M., 2006. Comparison of early and late toxic effects of sulfur mustard in Iranian veterans. Basic Clin. Pharmacol. Toxicol. 99, 273-282.

Beheshti, J., Mark, E.J., Akbaei, H.M., Aslani, J., Ghanei, M., 2006. Mustard lung secrets: long term clinicopathological study following mustard gas exposure. Pathol. Res. Pract. 202, 739-744.

Bhalla, D.K., 1999. Ozone-induced lung inflammation and mucosal barrier disruption: toxicology, mechanisms, and implications. J. Toxicol. Environ. Health B Crit. Rev. 2, 31-86.

Calvet, J.H., D'Ortho, M.P., Jarreau, P.H., Levame, M., Harf, A., Macquin-Mavier, I., 1994a Glucocorticoids inhibit sulfur mustard-induced airway muscle hyperresponsiveness to substance P. J. Appl. Physiol. 77, 2325-2332.

Calvet, J.H., Jarreau, P.H., Levame, M., D'Ortho, M.P., Lorino, H., Harf, A., Macquin-Mavier I., 1994b. Acute and chronic respiratory effects of sulfur mustard intoxication in guinea pig. J. Appl. Physiol. 76, 681-688.

Calvet, J.H., Coste, A., Levame, M., Harf, A., Macquin-Mavier, I., Escudier, E., 1996. Airway epithelial damage induced by sulfur mustard in guinea pigs, effects of glucocorticoids. Hum. Exp. Toxicol. 15, 964-971.

Calvet, J.H., Planus, E., Rouet, P., Pezet, S., Levame, M., Lafuma, C., Harf, A., D'Ortho, M.P. 1999. Matrix metalloproteinase gelatinases in sulfur mustard-induced acute airway injury in guinea pigs. Am. J. Physiol. 276, L754-L762.

Casillas, R.P., Kiser, R.C., Truxall, J.A., Singer, A.W., Shumaker, S.M., Niemuth, N.A., Ricketts, K.M., Mitcheltree, L.W., Castrejon, L.R., Blank, J.A., 2000. Therapeutic approaches to dermatotoxicity by sulfur mustard: I. Modulation of sulfur mustardinduced cutaneous injury in the mouse ear vesicant model. J. Appl. Toxicol. 20, S145-S151. 
Chatterjee, D., Mukherjee, S., Smith, M.G., Das, S.K., 2003. Signal transduction events in lung injury induced by 2-chloroethyl ethyl sulfide, a mustard analog. J. Biochem. Mol. Toxicol. 17, 114-121.

Chen, Z.H., Kim, H.P., Sciurba, F.C., Lee, S.J., Feghali-Bostwick, C., Stolz, D.B., Dhir, R. Landreneau, R.J., Schuchert, M.J., Yousem, S.A., Nakahira, K., Pilewski, J.M., Lee, J.S., Zhang, Y., Ryter, S.W., Choi, A.M., 2008. Egr-1 regulates autophagy in cigarette smoke-induced chronic obstructive pulmonary disease. PLoS ONE 3, e3316.

Chroneos, Z.C., Sever-Chroneos, Z., Shepherd, V.L., 2010. Pulmonary surfactant: an immunological perspective. Cell. Physiol. Biochem. 25, 13-26.

Corbel, M., Belleguic, C., Boichot, E., Lagente, V., 2002. Involvement of gelatinases (MMP-2 and MMP-9) in the development of airway inflammation and pulmonary fibrosis. Cell Biol. Toxicol. 18, 51-61.

Crouch, E.C., 2000. Surfactant protein-D and pulmonary host defense. Respir. Res. 1, 93-108.

Cusimano, E.M., Knight, A.R., Slusser, J.G., Clancy, R.L., Pierce, J.D., 2009. Mitochondria: the hemi of the cell. Adv. Emerg. Nurs. J. 31, 54-62.

Debiak, M., Kehe, K., Burkle, A., 2009. Role of poly(ADP-ribose) polymerase in sulfur mustard toxicity. Toxicology 263, 20-25.

Dillman, J.F., McGary, K.L., Schlager, J.J., 2003. Sulfur mustard induces the formation of keratin aggregates in human epidermal keratinocytes. Toxicol. Appl. Pharmacol. 193, 228-236.

Eisenmenger, W., Drasch, G., von Clarmann, M., Kretschmer, E., Roider, G., 1991. Clinical and morphological findings on mustard gas [bis(2-chloroethyl)sulfide] poisoning. J. Forensic Sci. 36, 1688-1696.

Fairhall, S.J., Brown, R.F., Jugg, B.J., Smith, A.J., Mann, T.M., Jenner, J., Sciuto, A.M., 2008 Preliminary studies of sulphur mustard-induced lung injury in the terminally anesthetized pig: exposure system and methodology. Toxicol. Mech. Methods 18, 355-362.

Gao, X., Ray, R., Xiao, Y., Ray, P., 2008. Suppression of inducible nitric oxide synthase expression and nitric oxide production by macrolide antibiotics in sulfur mustard-exposed airway epithelial cells. Basic Clin. Pharmacol. Toxicol. 103, $255-261$.

Gao, X., Ray, R., Xiao, Y., Ishida, K., Ray, P., 2010. Macrolide antibiotics improve chemotactic and phagocytic capacity as well as reduce inflammation in sulfur mustard-exposed monocytes. Pulm. Pharmacol. Ther. 23, 97-106.

Ghanei, M., Harandi, A.A., 2007. Long term consequences from exposure to sulfur mustard: a review. Inhal. Toxicol. 19, 451-456.

Ghanei, M., Adibi, I., Farhat, F., Aslani, J., 2008. Late respiratory effects of sulfur mustard: how is the early symptoms severity involved? Chron. Respir. Dis. 5, 95-100.

Goven, D., Boutten, A., Lecon-Malas, V., Boczkowski, J., Bonay, M., 2009. Prolonged cigarette smoke exposure decreases heme oxygenase-1 and alters Nrf2 and Bach1 expression in human macrophages: roles of the MAP kinases ERK(1/2) and JNK FEBS Lett. 583, 3508-3518.

Guignabert, C., Taysse, L., Calvet, J.H., Planus, E., Delamanche, S., Galiacy, S., d'Ortho, M.P., 2005. Effect of doxycycline on sulfur mustard-induced respiratory lesions in guinea pigs. Am. J. Physiol. Lung Cell. Mol. Physiol. 289, L67-L74.

Guo, C.J., Atochina-Vasserman, E.N., Abramova, E., Foley, J.P., Zaman, A., Crouch, E., Beers, M.F., Savani, R.C., Gow, A.J., 2008. S-nitrosylation of surfactant protein-D controls inflammatory function. PLoS Biol. 6, e266.

Hess, J.F., FitzGerald, P.G., 2007. Treatment of keratin intermediate filaments with sulfur mustard analogs. Biochem. Biophys. Res. Commun. 359, 616-621.

Kehe, K., Szinicz, L., 2005. Medical aspects of sulphur mustard poisoning. Toxicology 214, 198-209.

Kehe, K., Balszuweit, F., Steinritz, D., Thiermann, H., 2009. Molecular toxicology of sulfur mustard-induced cutaneous inflammation and blistering. Toxicology 263, 12-19.

Korkmaz, A., Yaren, H., Topal, T., Oter, S., 2006. Molecular targets against mustard toxicity: implication of cell surface receptors, peroxynitrite production, and PARP activation. Arch. Toxicol. 80, 662-670.

Kumar, S., 2007. Caspase function in programmed cell death. Cell Death Differ. 14 $32-43$.

Kumar, O., Sugendran, K., Vijayaraghavan, R., 2001. Protective effect of various antioxidants on the toxicity of sulphur mustard administered to mice by inhalation or percutaneous routes. Chem. Biol. Interact. 134, 1-12.

Laskin, D.L., Gardner, C.R., Laskin, J.D., 2010a. Phagocytes, In: Lawrence, D. (Ed.) Comprehensive Toxicology, 2nd edition. : Immune System Toxicology, vol. 5. Elsevier, UK, pp. 133-153.

Laskin, J.D., Heck, D.E., Laskin, D.L., 2010b. Nitric oxide pathways in toxic responses. In: Ballantyne, B., Marrs, T., Syversen, T. (Eds.), General and Applied Toxicology. WileyBlackwell, UK. Chapter 17.

McClintock, S.D., Hoesel, L.M., Das, S.K., Till, G.O., Neff, T., Kunkel, R.G., Smith, M.G., Ward, P.A., 2006. Attenuation of half sulfur mustard gas-induced acute lung injury in rats. J. Appl. Toxicol. 26, 126-131.
Mol, M.A., van den Berg, R.M., Benschop, H.P., 2008. Proteomic assessment of sulfur mustard-induced protein adducts and other protein modifications in human epidermal keratinocytes. Toxicol. Appl. Pharmacol. 230, 97-108.

Mukherjee, S., Stone, W.L., Yang, H., Smith, M.G., Das, S.K., 2009. Protection of half sulfur mustard gas-induced lung injury in guinea pigs by antioxidant liposomes. J. Biochem. Mol. Toxicol. 23, 143-153.

Mukhopadhyay, S., Hoidal, J.R., Mukherjee, T.K., 2006. Role of TNFalpha in pulmonary pathophysiology. Respir. Res. 7, 125.

Mukhopadhyay, S., Mukherjee, S., Smith, M., Das, S.K., 2008. Activation of MAPK/AP-1 signaling pathway in lung injury induced by 2 -chloroethyl ethyl sulfide, a mustard gas analog. Toxicol. Lett. 181, 112-117.

Nyska, A., Lomnitski, L., Maronpot, R., Moomaw, C., Brodsky, B., Sintov, A., Wormser, U., 2001. Effects of iodine on inducible nitric oxide synthase and cyclooxygenase- 2 expression in sulfur mustard-induced skin. Arch. Toxicol. 74, 768-774.

Oberley-Deegan, R.E., Regan, E.A., Kinnula, V.L., Crapo, J.D., 2009. Extracellular superoxide dismutase and risk of COPD. COPD 6, 307-312.

Ohbayashi, H., 2002. Matrix metalloproteinases in lung diseases. Curr. Protein Pept. Sci. 3, 409-421.

O'Neill, H.C., White, C.W., Veress, L.A., Hendry-Hofer, T.B., Loader, J.E., Min, E., Huang, J., Rancourt, R.C., Day, B.J., 2010. Treatment with the catalytic metalloporphyrin AEOL 10150 reduces inflammation and oxidative stress due to inhalation of the sulfur mustard analog 2-chloroethyl ethyl sulfide. Free Radic. Biol. Med. 48, 1188-1196.

Papirmeister, B., Feister, A.J., Robinson, S.I., Ford, R.D., 1991. Medical Defense Against Mustard Gas: Toxic Mechanisms and Pharmacological Implications. CRC Press, Boca Raton.

Ray, R., Keyser, B., Benton, B., Daher, A., Simbulan-Rosenthal, C.M., Rosenthal, D.S., 2008. Sulfur mustard induces apoptosis in cultured normal human airway epithelial cells: evidence of a dominant caspase-8-mediated pathway and differential cellular responses. Drug Chem. Toxicol. 31, 137-148.

Ray, R., Simbulan-Rosenthal, C.M., Keyser, B.M., Benton, B., Anderson, D., Holmes, W., Trabosh, V.A., Daher, A., Rosenthal, D.S., 2010. Sulfur mustard induces apoptosis in lung epithelial cells via a caspase amplification loop. Toxicology 271, 94-99.

Reddy, S.P., 2008. The antioxidant response element and oxidative stress modifiers in airway diseases. Curr. Mol. Med. 8, 376-383.

Rowell, M., Kehe, K., Balszuweit, F., Thiermann, H., 2009. The chronic effects of sulfur mustard exposure. Toxicology 263, 9-11.

Shakarjian, M.P., Heck, D.E., Gray, J.P., Sinko, P.J., Gordon, M.K., Casillas, R.P., Heindel, N.D., Gerecke, D.R., Laskin, D.L., Laskin, J.D., 2010. Mechanisms mediating the vesicant actions of sulfur mustard after cutaneous exposure. Toxicol. Sci. 114, 5-19.

Sinha Roy, S., Mukherjee, S., Kabir, S., Rajaratnam, V., Smith, M., Das, S.K., 2005. Inhibition of cholinephosphotransferase activity in lung injury induced by 2-chloroethyl ethyl sulfide, a mustard analog. J. Biochem. Mol. Toxicol. 19, 289-297.

Soldani, C., Scovassi, A.I., 2002. Poly(ADP-ribose) polymerase-1 cleavage during apoptosis: an update. Apoptosis 7, 321-328.

Sourdeval, M., Lemaire, C., Deniaud, A., Taysse, L., Daulon, S., Breton, P., Brenner, C., Boisvieux-Ulrich, E., Marano, F., 2006. Inhibition of caspase-dependent mitochondrial permeability transition protects airway epithelial cells against mustardinduced apoptosis. Apoptosis 11, 1545-1559.

Sunil, V.R., Patel, K.J., Malaviya, R., Laskin, J.D., Laskin, D.L., 2009. Inflammatory mediator expression in the lung following exposure to the sulfur mustard analog, 2-chloroethyl sulfide; Role of TNFR1. Am. J. Res. Crit. Care Med 179, A5863.

Torchinsky, M.B., Garaude, J., Blander, J.M., 2010. Infection and apoptosis as a combined inflammatory trigger. Curr. Opin. Immunol. 22, 55-62.

Uchiyama, Y., Shibata, M., Koike, M., Yoshimura, K., Sasaki, M., 2008. Autophagyphysiology and pathophysiology. Histochem. Cell Biol. 129, 407-420.

van Helden, H.P., Kuijpers, W.C., Diemel, R.V., 2004. Asthma like symptoms following intratracheal exposure of Guinea pigs to sulfur mustard aerosol: therapeutic efficacy of exogenous lung surfactant curosurf and salbutamol. Inhal. Toxicol. 16, 537-548.

Virgin, H.W., Levine, B., 2009. Autophagy genes in immunity. Nat. Immunol. 10, 461-470.

Wigenstam, E., Rocksen, D., Ekstrand-Hammarstrom, B., Bucht, A., 2009. Treatment with dexamethasone or liposome-encapsuled vitamin E provides beneficial effects after chemical-induced lung injury. Inhal. Toxicol. 21, 958-964.

Willems, J.L., 1989. Clinical management of mustard gas casualties. Ann. Med. Milit. (Belgium) 3, 1-61.

Wormser, U., Langenbach, R., Peddada, S., Sintov, A., Brodsky, B., Nyska, A., 2004. Reduced sulfur mustard-induced skin toxicity in cyclooxygenase-2 knockout and celecoxib-treated mice. Toxicol. Appl. Pharmacol. 200, 40-47.

Yourick, J.J., Dawson, J.S., Mitcheltree, L.W., 1995. Reduction of erythema in hairless guinea pigs after cutaneous sulfur mustard vapor exposure by pretreatment with niacinamide, promethazine and indomethacin. J. Appl. Toxicol. 15, 133-138. 